\title{
A DIALÉTICA ENTRE A INTERVENÇÃO PEDAGÓGICA NO JOGO DE PAPÉIS SOCIAIS E O DESENVOLVIMENTO DA PSIQUE INFANTIL
}

\author{
Silvio Sena ${ }^{1}$, Célia Maria Guimarães ${ }^{2}$ \\ ${ }^{1}$ Doutor em Educação pela Universidade Estadual Paulista - FCT/UNESP, Presidente Prudente, SP. Professor efetivo na \\ rede municipal de ensino de Presidente Prudente desde 1990, atualmente atua na formação continuada dos \\ profissionais da educação infantil e do Ensino Fundamental. E-mail: ssena1916@gmail.com \\ ${ }^{2}$ Doutora em Educação pela Universidade Estadual Paulista - FFC/UNESP. Pós-doutorado pela Universidade de Lisboa- \\ Portugal e pela Escola Superior de Educação do Instituto Politécnico de Santarém-PT. Professora do Programa de Pós- \\ Graduação em Educação da Universidade Estadual Paulista - FCT/UNESP, Presidente Prudente, SP.
}

\section{RESUMO}

Este artigo descreve parte da pesquisa de doutorado, respaldada no enfoque histórico-cultural. A investigação analisou as interferências da intervenção pedagógica no jogo de papéis para o desenvolvimento psíquico de vinte crianças de uma turma de pré-escola. A metodologia se caracterizou como pesquisa-intervenção e os dados advieram de observação participante, registros em caderno de campo, fotografias e filmagens. Os resultados comprovaram que a adequada intervenção pedagógica no jogo de papéis promove o nível de jogo e o desenvolvimento da psique infantil. Assim, confirmou-se a tese de que "a intervenção do(a) professor(a) pré-escolar no jogo de papéis não deve se limitar à circunscrição da organização prévia dos espaços e dos materiais para a efetivação do brincar infantil. Além disso, cabe a esse(a) professor(a) intervir de forma indireta e direta nessa espécie de atividade, com vistas a promover o avanço do nível do jogo de papéis e, por consequência, o desenvolvimento psíquico da criança pré-escolar". Desse modo, a pesquisa clarificou o movimento dialético causado pelos elementos envolvidos na simultaneidade dos avanços do nível de jogo e do psiquismo infantil, o que serve de amparo para a formação teórica e a constituição-aprimoramento da práxis pedagógica dos professores da educação infantil e dos estudantes dos cursos de pedagogia e áreas afins.

Palavras-chave: Educação. Educação Infantil. Criança Pré-escolar. Intervenção Pedagógica. Jogo de Papéis Sociais.

\section{THE DIALECTICS BETWEEN THE PEDAGOGICAL INTERVENTION IN THE GAME OF SOCIAL PAPERS AND THE DEVELOPMENT OF THE CHILD PSYCHE}

\begin{abstract}
This article describes part of the doctorate research study, supported by the historical-cultural approach. The research analyzed the interference of pedagogical intervention in role-playing for the psychic development of twenty children from a pre-school class. The methodology was an intervention research and the data came from participant observation, in-field record notebook, photographs and filming. The results proved that the adequate pedagogical intervention in role-playing promotes the level of playing and the development of the child psyche. Thus, the thesis confirmed was that "the intervention of the preschool teacher in role-playing should not be limited to the circumscription of the previous organization of spaces and materials for the effective play of the children. In addition, it is up to this teacher to intervene indirectly and directly on this kind of activity, in order to promote the advancement of the level of role-play and, consequently, the psychic development of the pre-school child". This way, the research clarified the dialectic movement caused by the elements involved in the simultaneity of the advances of the level of playing and the infant psyche, which serves as a support for the theoretical formation and the constitutionimprovement of the pedagogical praxis of the children's education teachers and students of pedagogy courses and related areas.
\end{abstract}

Keywords: Education. Child education. Preschool Child. Pedagogical Intervention. Social Role-Playing Game. 


\section{LA DIALÉTICA ENTRE LA INTERVENCIÓN PEDAGÓGICA EN EL JUEGO DE PAPELES SOCIALES Y EL DESARROLLO DE PSIQUE INFANTI}

\section{RESUMEN}

Este artículo describe parte de la investigación de doctorado, respaldada en el enfoque histórico-cultural. La investigación analizó las interferencias de la intervención pedagógica en el juego de papeles para el desarrollo psíquico de veinte niños de una clase de preescolar. La metodología se caracterizó como investigación-intervención y los datos proceden de la observación participante, registros en cuaderno de campo, fotografías y filmaciones. Los resultados comprobaron que la adecuada intervención pedagógica en el juego de papeles promueve el nivel de juego y el desarrollo de la psique infantil. Así, se confirmó la tesis de que "la intervención del (a) profesor (a) preescolar en el juego de papeles no debe limitarse a la circunscripción de la organización previa de los espacios y de los materiales para la efectividad del juego infantil. Además, corresponde a ese (a) profesor (a) intervenir de forma indirecta y directa en esa actividad, con ganas en promover el avance del nivel del juego de papeles y, por consiguiente, el desarrollo psíquico del niño preescolar". De este modo, la investigación aclaró el movimiento dialéctico causado por los elementos involucrados en la simultaneidad de los avances del nivel de juego y del psiquismo infantil, lo que sirve de apoyo a la formación teórica y la constitución-perfeccionamiento de la praxis pedagógica de los profesores de la educación infantil y de los niños estudiantes de los cursos de pedagogía y áreas afines.

Palabras clave: Educación. Educación Infantil. Niños preescolares. Intervención pedagógica. Juego de Papeles Sociales.

\section{INTRODUÇÃO}

Neste texto, descrevemos parte da nossa pesquisa de doutorado em educação, denominada "A dialética entre a intervenção pedagógica no jogo de papéis $^{1}$ e o desenvolvimento psíquico da criança contemporânea em idade pré-escolar" ${ }^{2}$

Para tanto, destacamos a forma de proceder ao ato da intervenção pedagógica no brincar apresentada pela tese e suas implicações, para o avanço do nível de jogo da criança em idade pré-escolar. Avanço este, que segundo Elkonin (2009), de maneira intima e simultânea repercute em aquisições e reestruturações internas no psiquismo infantil.

Nessa proposição, partimos do pressuposto de que a personalidade humana se forma por meio de um processo estreitamente vinculado às atividades realizadas pelo indivíduo. Atividades estas, que se iniciam com 0 nascimento e se estendem ao longo de toda sua

\footnotetext{
${ }^{1}$ As palavras brincadeira e jogo possuem um caráter bem mais amplo que a atividade lúdica com situação imaginaria (fictícia), na qual a criança assume papéis de personagens genéricos. Desse modo, quando não especificadas, essas palavras e as expressões jogo protagonizado e jogo de papéis correspondem e são sinônimas da atividade conceituada no meio acadêmico como jogo de papéis sociais.

${ }^{2}$ Essa pesquisa se encontra integralmente disponível no endereço https://repositorio.unesp.br/handle/11449/153067.
}

vida, por meio das quais, ao se relacionar com o outro ele se apropria da cultura, se humanizando.

Ao considerar os processos interativos e a brincadeira como atividades-eixo da educação infantil, bem como o jogo de papéis sociais como atividade-guia do desenvolvimento psíquico da criança contemporânea em idade pré-escolar, nos vimos inquietados pela questão: "O jogo de papéis tem sido considerado como atividade-guia do psiquismo da criança em idade pré-escolar nas escolas de educação infantil?"

Movidos por essa inquietação, realizamos levantamento dos trabalhos produzidos de janeiro de 2009 a dezembro de 2012 que abordassem a brincadeira da criança da/na Educação Infantil, com especial relevo ao período pré-escolar, nos bancos de dados dos periódicos WebQualís A1, A2, B 1 e B 2; das dissertações e teses originárias dos Programas de PósGraduação brasileiros recomendados e avaliados pela CAPES com nota igual ou superior a "4"; e, dos arquivos da Associação Nacional de PósGraduação e Pesquisa em Educação (ANPEd).

Localizamos vinte e seis produções, sendo nove artigos de periódicos, nove dissertações, duas teses de doutoramento e seis trabalhos indexados nas reuniões anuais da ANPEd. Ao analisá-las, observamos consenso no reconhecimento do valor do brincar para o desenvolvimento infantil. Contudo, constatamos 
apenas uma a ilustrar formas de se praticar intervenções no brincar infantil. Porém, não direcionadas ao jogo de papéis sociais.

Assim, confirmamos a situação problema da pesquisa, revelada na inexistência de trabalhos publicados no período de 2009 a 2012, cujo "objeto" de pesquisa seja a intervenção pedagógica indireta e direta do(a) professor(a) no jogo de papéis sociais, de modo a fazer valer as características que conformam esse fenômeno como atividade-guia ${ }^{3}$ do desenvolvimento psíquico da criança contemporânea em idade pré-escolar.

Ao efetuar a análise dos trabalhos advindos do mapeamento realizado e de leituras complementares, percebemos que em significativo percentual dos casos $\mathrm{o}$ ato da intervenção pedagógica se reduz à ação indireta de preparar-organizar previamente os espaços e os materiais para que o brincar suceda ao encontro da zona de desenvolvimento iminente $\left(Z D I^{4}\right)$ das crianças; e, à posterior observação e formulação de registros dessa forma de atividade.

Concordamos que esse modelo de intervenção exige amplo e consistente conhecimento psicogenético do desenvolvimento infantil e dos limites e possibilidades da brincadeira no contexto da educação infantil. Todavia, essa prática representa apenas uma das formas de se realizar $o$ ato da intervenção pedagógica no jogo de papéis.

Com base no levantamento bibliográfico e em leituras complementares, reparamos que em significativo número dos casos, as práticas se assentam em elementos externos e não em seu maior atributo educativo. Obstante a essa situação, os autores da pedagogia históricocrítica ratificam que às escolas de todas as etapas e níveis educativos, cabe assegurar as condições necessárias para o desenvolvimento de seus aprendizes em suas máximas possibilidades (MARTINS, 2015).

Assim confirmamos a relevância científica, pedagógica, política e social do

\footnotetext{
${ }^{3}$ A atividade-guia é aquela em conexão com “[...] as mais importantes mudanças no desenvolvimento psíquico da criança e dentro da qual se desenvolvem processos psíquicos que preparam o caminho da transição da criança para um novo e mais elevado nível de desenvolvimento". (LEONTIEV, 2012, p. 122).

${ }^{4}$ Segundo Vygotsky (2007), a ZDI se encontra latente na distância entre o nível de desenvolvimento "real", que se costuma determinar por meio da solução independente de problemas, e o nível de desenvolvimento "iminente", determinado através da capacidade da criança de solucionar problemas sob a orientação de um adulto ou em colaboração com coetâneos mais experientes.
}

"objeto" de estudo da pesquisa (a intervenção pedagógica indireta e direta no brincar da criança contemporânea em idade pré-escolar) como condição para o reconhecimento do valor do brincar para o desenvolvimento psíquico das crianças (alunos) em idade pré-escolar.

Desse encadeamento de ideias começamos a tecer a tese da pesquisa, com base no pressuposto de que a intervenção pedagógica do(da) professor(a) pré-escolar no jogo de papéis não deve se limitar à circunscrição da organização prévia dos espaços e dos materiais (brinquedos), para a efetivação do brincar infantil. Além disso, cabe a esse(a) professor(a) intervir de forma indireta e direta nessa espécie de atividade, com vistas a promover o avanço do nível do jogo de papéis e, por consequência, a psique das crianças contemporâneas em idade pré-escolar.

Com o estabelecimento desses pontos de partida e embasados no enfoque históricocultural, buscamos uma forma de intervenção que viesse a gradualmente possibilitar o progresso da criança, do jogo no plano individual ao desenvolvido em parceria; de modo a interrelacionar os avanços nessa forma de atividade com as promoções qualitativas do psiquismo infantil.

Para tanto, elaboramos o objetivo geral e os específicos. Por meio do geral analisamos e interpretamos as interferências da intervenção pedagógica no jogo de papéis, para o desenvolvimento psíquico da criança contemporânea em idade pré-escolar. Com os específicos intervimos e mensuramos a partir dos elementos estruturais do jogo de papéis, o nível de jogo praticado pela criança contemporânea em idade pré-escolar; e, estabelecemos, de maneira dialética e integrada, a correlação entre o avanço do nível de jogo praticado e os elementos que medeiam, conformam e estruturam a psique infantil.

\section{METODOLOGIA}

A pesquisa se caracterizou como pesquisa-intervenção, se beneficiando da participação de vinte crianças de uma turma de pré-escolares com idade de três anos e dez meses a quatro anos e dois meses.

Os dados advieram de observação participante, de registros cursivos em caderno de campo, de fotografias e de filmagens. Vale frisar que as imagens provenientes das crianças foram usadas após a submissão e respectivo deferimento do Parecer Consubstanciado do 
Comitê de Ética em Pesquisa (CEP) no 644.590 de 09/05/2014.

Tomando por referência de análise os quatro níveis de desenvolvimento de cada elemento estrutural do jogo de papéis sociais (caráter das ações; utilização de objetos substitutos; adoção de um papel; e, relação com os coetâneos) concebidos por Elkonin (2009), identificamos o nível de atuação da criança e sua evolução no jogo como variável dependente ${ }^{5}$, de maneira a outorgar à particularidade da intervenção pedagógica no jogo de papéis sociais, o status de principal recurso pedagógico (variável independente).

O trabalho empírico teve seu início em julho de 2014 e seu arremate em dezembro do mesmo ano, com ao menos uma e no máximo duas sessões (aulas) semanais de uma hora. Perfez vinte e seis sessões, sendo composto pelas seguintes fases: 1 1a) fase de constatação diagnóstica inicial (FCDI): ocorreu nas quatro primeiras semanas - seis sessões; 2a) fase de intervenção (FI): principiou a partir da quinta semana - quinze sessões; e $3 \underline{a}$ ) fase de constatação diagnóstica conclusiva (FCDC): permeou as últimas três semanas - cinco sessões.

A investigação foi organizada com vistas a possibilitar a análise comparativa do nível dos elementos estruturais do jogo de papéis averiguado na FCDI, com o obtido na FCDC. Para isso, acolheu por referência os indicadores de desenvolvimento listados para cada categoria de análise (elemento estrutural) do jogo de papéis, em destaque:

- Caráter das ações: $1^{\circ}$ nível - ações de manipulação sem um conteúdo definido, $2^{\circ}$ nível - ações isoladas ou repetitivas com conteúdo definido, de caráter exclusivamente objetal, $\underline{3^{\circ} \text { nível - ações }}$ lúdicas sem sentido lógico, concatenadas a um papel específico, $4^{\circ}$ nível sequências de ações com tendência a reproduzir a lógica da vida real, inseridas em um argumento determinado.

- Utilização de objetos substitutos: $\underline{1}^{\circ}$ nível - não os utilizam, $2^{\circ}$ nível - usam alguns objetos substitutos em situações imaginárias, todavia, sem denominá-los segundo a função que realizam, $3^{\circ}$ nível empregam objetos substitutos em

\footnotetext{
${ }^{5}$ Apoiados em Kerlinger (1979), podemos dizer que a variável dependente pode ser definida como aquela afetada ou explicada pela variável independente, a qual, por sua vez, se consubstancia naquela que afeta outra variável, chamada variável dependente.
}

situações imaginárias habituais e os denominam de acordo com a sua função, $4^{\circ}$ nível - criam circunstâncias lúdicas, nas quais se manifestam as diversas formas de situações.

- Adoção de um papel: $\underline{1}^{\circ}$ nível - o papel não está presente, $\underline{2}^{\circ}$ nível - o papel está presente apenas no conteúdo das ações que realizam, $3^{\circ}$ nível - atribuem o nome do papel ao qual estão referidas as ações que realizam, $4^{\circ}$ nível - atuam em consequência dos papéis assumidos e se denominam pelo nome social outorgado a estes.

- Relações com os coetâneos: $1^{\circ}$ nível consistem em breves contatos casuais, respaldados em motivos não lúdicos, $\underline{2}^{\circ}$ nível - surgem casualmente em ações recíprocas, porém, não referidas a um papel, $3^{\circ}$ nível - ocorrem casualmente, implícitas em ações lúdicas, com ou sem verbalização, $4^{\circ}$ nível - surgem a partir dos papéis assumidos e incluem a comunicação amparada em ações, que seguem a lógica do argumento.

Nas fases isentas de caráter interventivo ( $F C D I$ e FCDC), tivemos o cuidado de assegurar a mesma metodologia e instrumentos/procedimentos metodológicos.

Quanto à fase planejada especificamente para efetuar a intervenção pedagógica no jogo de papéis (FI), o estudo propôs $O$ ato interventivo organizado nos sequentes três momentos: o primeiro se revelou na roda de conversa - intervenção indireta; o segundo se traduziu no momento destinado à organização-preparação conjunta (professor e crianças) do cenário do brincar acordado às temáticas das tramas manifestadas - intervenção direta; e o terceiro caracterizou-se pela intervenção, também direta, do professor pesquisador e/ou da professora-regular (professora referência da turma de crianças que participaram da investigação) no jogo de papéis, durante o seu transcurso.

\section{RESULTADOS}

$\mathrm{Na}$ análise dos dados, fizemos um esforço para atentar que os contrários se interpenetram e em suas partes e em seu todo, a quantidade se transforma em qualidade e vice-versa, gerando a permanente tensão da negação da negação.

Por meio desse olhar, mensuramos a 
essencialidade concreta das implicações da intervenção pedagógica no jogo de papéis para a subjetividade das crianças, a partir da decodificação da totalidade à luz da dialética singularidade-particularidade-universalidade.

Buscamos explicar como a singularidade do desenvolvimento infantil se constrói através do brincar e, ao mesmo tempo e da mesma forma, como a universalidade, conformada pelos elementos estruturais do jogo de papéis, se concretiza na singularidade da subjetividade da criança em idade pré-escolar, pelas repercussões causadas pela particularidade da especificidade da intervenção pedagógica nessa espécie de atividade.

Assinalando o primeiro ciclo de análise, imediatamente após o término de cada sessão de trabalho, com amparo na memória e nas imagens contextuais incididas do jogo de papéis, o relatório descritivo de cada sessão foi composto à luz dos princípios e pressupostos do enfoque histórico-cultural.

Correspondendo ao segundo ciclo de análise, praticou-se a análise da análise. Isso quer dizer que incontáveis vezes visitamos os dados, a fim de confirmar ou readequar as conclusões. Com apoio no enfoque histórico-cultural e no método crítico-dialético, em oposiçãocontradição com as categorias de análise específicas, procedemos à pré-análise dos dados contidos na totalidade dos relatórios, com base na memória, nos registros escritos e nas imagens geradas pelo brincar infantil. Essas análises, descritivo-interpretativas com ênfase na dimensão instrucional, se referiram à implicação da intervenção pedagógica no jogo de papéis para o nível de jogo praticado pelas crianças, segundo os indicadores de desenvolvimento das categorias de análise específicas.

De maneira objetiva, averiguamos as implicações da particularidade da intervenção pedagógica no brincar infantil para o nível de jogo exibido pelas crianças, na fase conclusiva da investigação (FCDC), em comparação com a fase inicial (FCDI).

No processo de análise dos relatórios e das imagens do brincar infantil, nos vimos com dificuldade para situar o jogo praticado pelas crianças em determinado nível das categorias de análise específicas, uma vez que, quando em certo encontro as ações de algumas delas estiveram na direção do 2 o nível, na mesma sessão e em outras, frequentemente, coexistiram sinais lúdicos relacionados aos outros níveis. Diante dessa dificuldade, estimamos o nível predominante de jogo expressado na conjuntura das sessões consideradas no processo de análise.

Quanto ao posicionamento da criança em determinado nível de cada categoria de análise específica, ao longo das fases que compuseram a empiria, se faz importante salientar que utilizamos os episódios selecionados e as sessões respectivas de maneira transversal. $O$ uso dessa forma de análise não ocorreu para suprir uma suposta escassez de tramas que contivessem situações capazes de figurar como amostragens dos níveis dos elementos estruturais do jogo de papéis. Empregamos os mesmos episódios para evidenciar o caráter interdependente que articula a conjuntura das categorias de análise específicas como unidade do jogo de papéis.

Como aponta o Gráfico 1, na categoria caráter das ações, na FCDI, das dezoito crianças, treze $(72,22 \%)$ se localizavam no 2 을el e cinco $(27,78 \%)$, no 3 ㅇ.

Gráfico 1. Caráter das ações

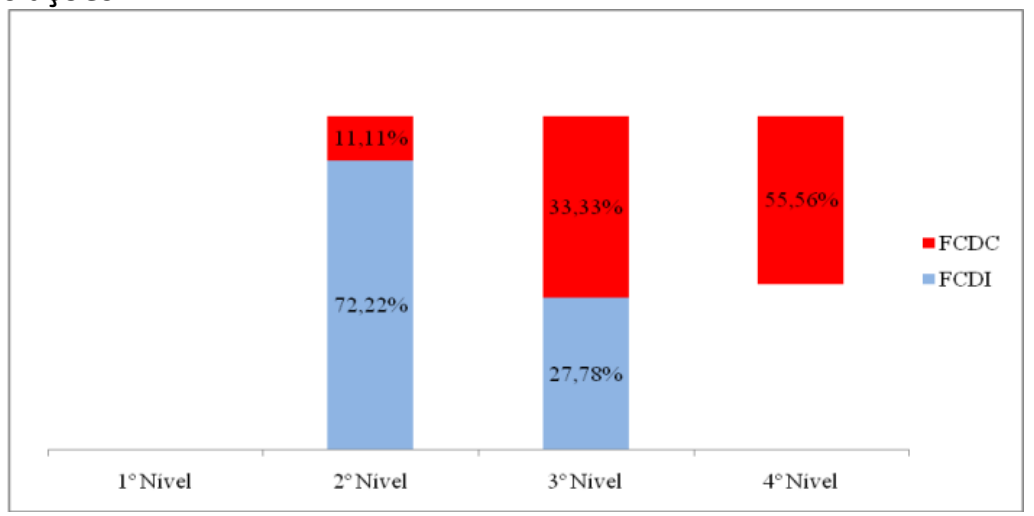

Fonte: Dados gerados pela pesquisa (SENA, 2018). 
Na FCDC, das treze $(72,22 \%)$ crianças que haviam se posicionado no 2 o nível, na FCDI, 11 $(61,11 \%)$ avançaram no nível de jogo, de sorte a restarem apenas duas $(11,11 \%)$ naquele nível. 0 resultado mais expressivo é notado na inexistência de crianças no 40 nível, na FCDI, e na decorrente presença, na FCDC, de dez $(55,56 \%)$ delas nesse nível de jogo.

O Gráfico 2 demonstra que, na FCDI, na categoria utilização de objetos substitutos, observamos treze $(72,22 \%)$ crianças no 20 nível e cinco $(27,78 \%)$, no 3 ․

Gráfico 2. Utilização de objetos substitutos

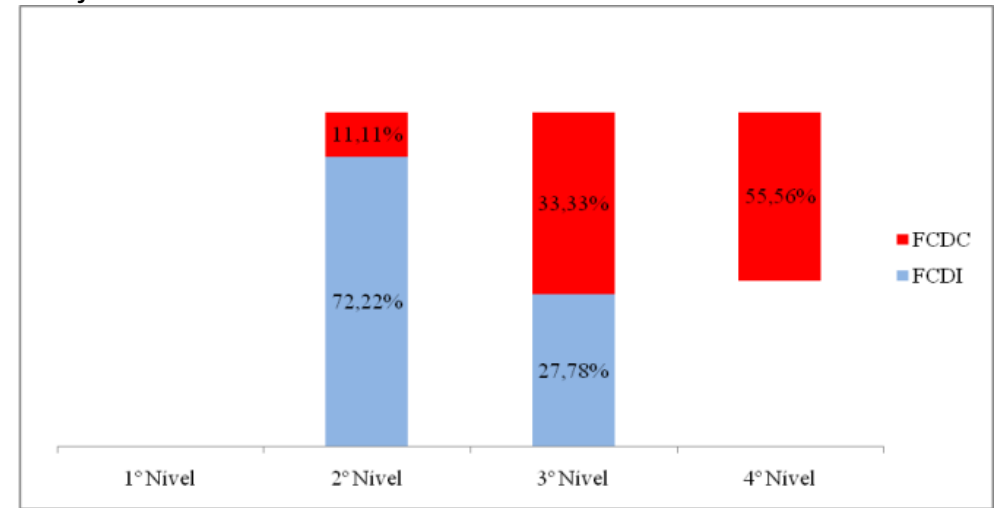

Fonte: Dados gerados pela pesquisa (SENA, 2018).

Em razão da transposição de crianças para níveis superiores de jogo, notamos, na FCDC, o expressivo decréscimo do número delas no 2 응 nível, de treze $(72,22 \%)$ para apenas duas $(11,11 \%)$. Quanto às crianças que se situavam no 3o nível, o número foi ampliado de cinco $(27,78 \%)$, na $F C D I$, para seis $(33,33 \%)$, na FCDC. Semelhante ao encontrado na categoria caráter das ações, na FCDI, nenhuma criança foi posicionada no 4 o nível de jogo. Entretanto, contabilizamos dez $(55,56 \%)$ delas, na FCDC.

No que concerne à categoria adoção de um papel, como valida o Gráfico 3, na FCDI, verificamos que quatorze $(77,78 \%)$ crianças se encontravam no 2 을el e quatro $(22,22 \%)$, no 3ㅇ.

Gráfico 3. Adoção de um papel

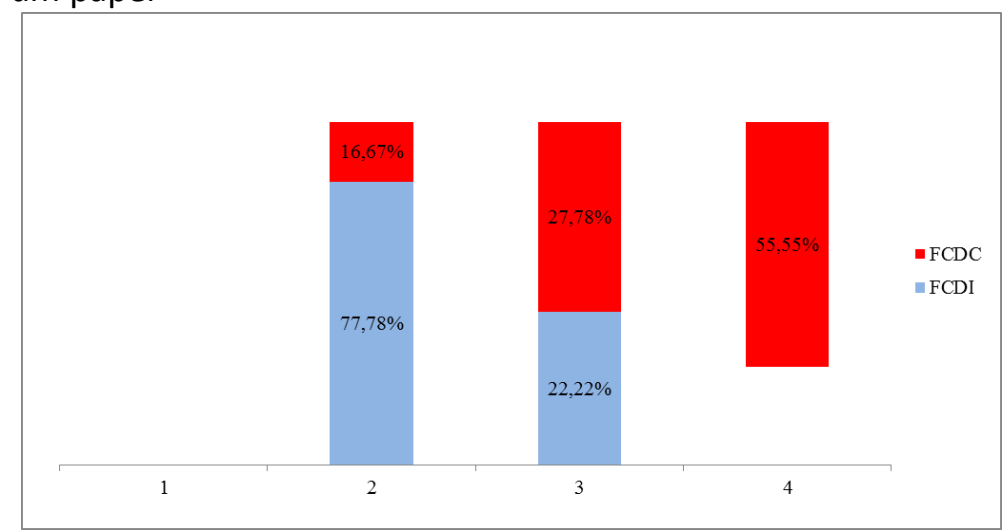

Fonte: Dados gerados pela pesquisa (SENA, 2018).

Das quatorze crianças que se estavam no 20 nível da categoria adoção de um papel, onze $(61,11 \%)$ migraram para níveis superiores de jogo, de modo a restarem apenas três $(16,67 \%)$, na FCDC. Também constatamos que o número de crianças que se situavam no 3 o nível foi elevado, de quatro $(22,22 \%)$, na FCDI, para cinco $(27,78 \%)$, na FCDC. Similarmente ao percebido nas categorias caráter das ações e utilização de objetos substitutos, na FCDI, nenhuma criança foi posicionada no 4음ível de jogo. No entanto, na FCDC, dez $(55,55 \%)$ delas passaram a agir em consequência dos papéis assumidos e se denominando de acordo com o nome social 
outorgado a esses papéis.

no 2 ํ́vel e três $(16,67 \%)$, no 3 .

$\mathrm{Na}$ categoria relação com os coetâneos,

na $\mathrm{FCDI}$, encontramos quinze $(83,33 \%)$ crianças

Gráfico 4. Relação com os coetâneos

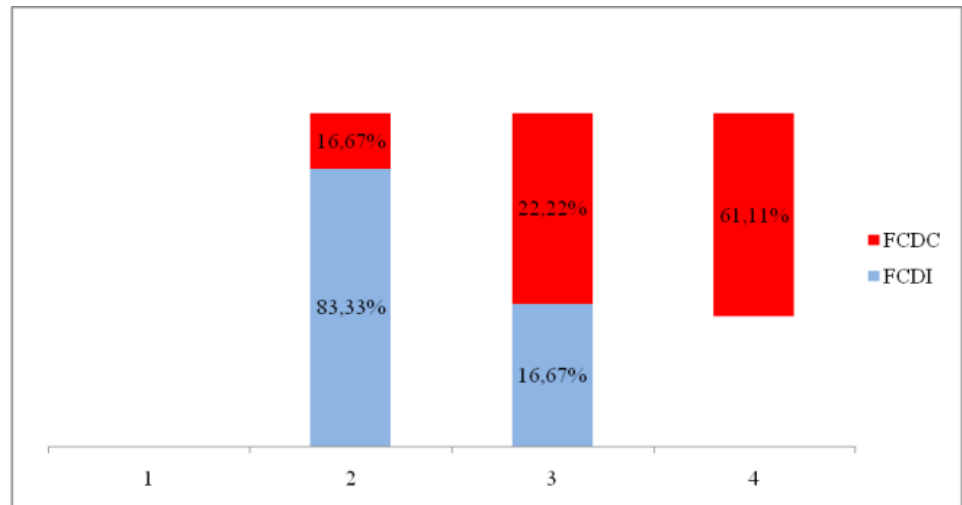

Fonte: Dados gerados pela pesquisa (SENA, 2018).

Conforme se verifica no Gráfico 4, das que estavam no 2o nível, treze $(72,22 \%)$ avançaram para níveis mais elevados de jogo, de sorte a restarem apenas três $(16,67 \%)$, na FCDC. Também percebemos um tímido aumento do número de crianças que ocupavam o 30 nível na FCDI, avançando na FCDC, de três $(16,67 \%)$ para quatro $(22,22 \%)$.

Em situação congênere às demais categorias, enquanto, na $\mathrm{FCDI}$, não havia nenhuma criança no 4o nível, na FCDC, localizamos onze $(61,11 \%)$ delas apresentando o brincar nesse nível de elaboração, no qual as ações se articulam com a atitude adotada pela criança "[...] em face de outras pessoas cujos papéis são interpretados por outras crianças" (ELKONIN, 2009, p. 298); quer dizer, as relações surgem a partir dos papéis assumidos, incluindo a comunicação amparada em ações com objetos substitutos carreadas pela lógica do argumento.

Por meio da intervenção pedagógica dimensionada à ZDI das crianças, apuramos que, das onze $(61,11 \%)$ que atingiram o 4 o nível das categorias de análise específicas, na FCDC, oito $(44,44 \%)$ já haviam alcançado esse nível, nas cinco primeiras sessões da Fl. Ao nosso ver, por influência da particularidade da intervenção pedagógica no jogo de papéis, o número de crianças envolvidas em um mesmo tema/episódio rapidamente se ampliou, de sorte a se observar, em várias situações, a superação do número de três crianças atuando em uma mesma série interativa. Frise-se que tal constatação superou nossas expectativas, pois a aguardavamos somente nas sessões próximas ao encerramento da empiria.
Assim, a conjuntura que integrou o arcabouço teórico e os resultados alcançados, de maneira reiterativa e complementar, comprovou a relevância e a pertinência da intervenção pedagógica no brincar da criança em idade préescolar.

Ao rumar para o próximo item, podemos sustentar que o conjunto do experimento mostrou que, ao terem o jogo enriquecido pelas intervenções realizadas e pela inserção de suas experiências pessoais, as crianças apresentaram mais interesse e avanços, no nível de jogo e de suas psiques.

\section{DISCUSSÃO}

Ao analisar os dados, fizemos um esforço para atentar que, em suas partes e em seu todo, a quantidade se transforma em qualidade (e viceversa) e os contrários se interpenetram, gerando a permanente tensão da negação da negação.

Por meio desse olhar, mensuramos a essencialidade concreta das implicações da intervenção pedagógica no jogo de papéis para a subjetividade das crianças, a partir da decodificação da totalidade à luz da dialética singularidade-particularidade-universalidade.

Buscamos explicar como a singularidade do desenvolvimento infantil se constrói através do brincar e, ao mesmo tempo e do mesmo modo, como a universalidade, conformada pelas premissas constituintes do brincar infantil, na perspectiva de Elkonin (2009), se concretiza na singularidade da subjetividade da criança contemporânea em idade pré-escolar, pelas repercussões causadas pela particularidade da especificidade (específico) da intervenção 
pedagógica no jogo de papéis.

Em consonância com Carvalho (2007, p. 182, grifo do autor), consideramos que, para conhecer "[...] a transversalidade conectiva do todo, não se faz necessário - e nem é possível percorrer, como uma listagem, todas as inúmeras partes, elementos, momentos e relações do todo, pois se trata de conhecer a lógica que preside a sua conexão."

Substituímos o método da decomposição do todo em elementos pela perspectiva sistêmica, a qual desmembra esse todo em unidades que conservam as propriedades fundamentais do jogo como unidade e atividadeguia, no processo de formação da psique da criança em idade pré-escolar.

Em todas as fases da investigação, tivemos o cuidado de efetuar a análise dos dados, de sorte a assegurar a lógica do movimento dialético latente entre os elementos que conformam o enfoque histórico-cultural. Valemonos da sugestão de Ades (2009), alternando a observação empírica com a observação interpretativa, obtida pela inserção de observação participante, de registros cursivos e da captação de imagens (fotografias e filmagens) em contextos holísticos.

Enquanto a professora-regular praticou o ato da intervenção pedagógica, procedemos ao ato do registro e vice-versa, de modo a apreender o real empírico (imediato), pela observação e a produção de imagens (filmagem e fotografias) incididas do universo contextual no qual se encontrou inserido o brincar infantil. Esse plano exprimiu os dados empíricos imediatos resultantes dos fatos extraídos daquela realidade, os quais,

[...] convertidos em objeto de análise por meio dos processos de abstração resultam numa apreensão superior, expressa-se como concreto

pensado. Porém, esta não é a etapa final do processo, uma vez que as categorias interpretativas, as estruturas analíticas constitutivas do concreto pensado serão contrapostas em face do objeto inicial, agora captado não mais em sua imediatez mas, em sua totalidade concreta. (MARTINS, 2015 , p. 23, grifos da autora).

Nessa intencionalidade e assinalando o primeiro ciclo de análise, imediatamente após o término de cada sessão de trabalho, compusemos o relatório descritivo de cada sessão, amparados na memória e nas imagens contextuais incididas do jogo de papéis; de modo consensual com a professora-regular e à luz dos princípios e pressupostos do enfoque históricocultural e dos procedimentos metodológicos adotados.

Correspondendo ao segundo ciclo de análise, praticamos a análise da análise. Isso quer dizer que incontáveis vezes revisitamos os dados, a fim de confirmar ou readequar as conclusões das análises realizadas. Com apoio no enfoque histórico-cultural e nas categorias do método crítico-dialético (movimento, oposiçãocontradição, específico, dialética singularidadeparticularidade-universalidade e totalidade) em oposição-contradição com as categorias de análise específicas (caráter das ações, utilização de objetos substitutos, adoção de um papel e relação com os coetâneos), procedemos à préanálise dos dados contidos na totalidade dos relatórios, com base na memória, nos registros e nas imagens geradas. Essas análises descritivointerpretativas, com ênfase na dimensão instrucional, se referiram à implicação da intervenção pedagógica no jogo de papéis para o nível de jogo praticado pelas crianças, segundo os indicadores de desenvolvimento das categorias de análise acima citadas.

De acordo com Pino (2005), a análise interpretativa implica duas posturas metodológicas: 1a - o objetivo da pesquisa não é a análise de fatos, mas de processos, ou seja, da história da gênese desses fatos. A ideia de processo equivale à gênese histórica do fato pesquisado; é no estudo dessa gênese que se capturam a natureza e a significação desse fato. "Isso equivale a dizer que o procedimento metodológico é histórico genético, uma vez que o processo de gênese de um fato humano constitui a história desse fato." (PINO, 2005, p. 179); 2a contrapor à análise descritiva dos problemas a análise explicativa. "A primeira fica na exterioridade dos fenômenos, ou seja, no seu 
aspecto fenomenal ou aparente; a segunda penetra no interior deles, na sua dinâmica e gênese histórica ou essência." (PINO, 2005, p. 179). De maneira sintética, a abordagem metodológica coerente com o enfoque históricocultural deve partir da dialética históricogenética.

Nessa tendência, Elkonin (2009) examina os dados de seus experimentos segundo os quatro níveis dos indicadores de desenvolvimento do jogo de papéis, dos quais também nos utilizamos, para mensurar o brincar infantil em acordo com as categorias de análise específicas.

$\mathrm{Na}$ perspectiva apontada, o item imediato exibe o nível do brincar das crianças, aferido na $\mathrm{FCDI}$, em comparação com $\mathrm{o}$ constatado na FCDC. Para isso, nós nos valemos de amostragens de situações propiciadas pelo brincar, em íntima relação de interdependência com as categorias dialéticas e as de análise específicas e seus respectivos indicadores de desenvolvimento do jogo de papéis.

\section{Mensuração do nível de desenvolvimento do jogo de papéis}

Com base no enfoque histórico-cultural, este item contém a análise dos dados produzidos ao longo das três fases que conformaram a empiria. Para assegurar a apresentação e a discussão fundamentada dos dados, primeiramente, retomamos a lógica dialética empregada na intervenção pedagógica no jogo de papéis, ao longo das quinze sessões que compuseram a FI. A partir da obtenção dos dados, esmiuçamos o raciocínio usado na apreciação do nível das quatro categorias de análise específicas (caráter das ações, utilização de objetos substitutos, adoção de um papel e relação com os coetâneos), de modo a comparar os resultados da fase inicial (FCDI) com os obtidos na fase conclusiva (FCDC) do trabalho empírico.

De forma objetiva, averiguamos as implicações quali-quantitativas da particularidade da intervenção pedagógica no brincar infantil, para o nível de jogo exibido pelas crianças na fase conclusiva ( $F C D C)$ e, por consequência, para os processos de humanização (desenvolvimento psíquico) das dezoito crianças que tiveram o brincar sob o crivo de nossa observação, intervenção e análise, durante as três fases que compuseram o trabalho de campo. Em outras palavras, este item contempla o objetivo específico de "estabelecer, de maneira dialética e integrada, a correlação entre o avanço do nível de jogo praticado e os elementos que medeiam e conformam o processo de humanização da criança em idade pré-escolar, na tendência do enfoque histórico cultural, a saber: o biológico, o histórico-cultural e a atividade."

Nessa intenção, ilustramos o processo avaliativo dos dados da pesquisa em acordo com a universalidade oportunizada pelos indicadores de desenvolvimento das quatro categorias de análise específicas, que conformam o jogo de papéis, na perspectiva de Elkonin (2009).

Em harmonia com a visão sistêmica do jogo e do desenvolvimento humano, compusemos um conjunto de relatórios que demonstram como o experimento foi realizado e a inegável implicação da intervenção pedagógica no aspecto qualitativo do brincar e do psiquismo das crianças submetidas ao experimento.

A fim de atender a esse propósito, tornase fundamental compreender que, da gênese ao ápice do jogo de papéis, de maneira gradativa e concomitante, a criança avança da percepção fragmentada e difusa da realidade para aquela que lhe permite perceber totalidades cada vez mais amplas e inclusivas.

Ao intervir no jogo em sintonia com o enfoque histórico-cultural, notamos que, da fase inicial à conclusiva, não houve crianças posicionadas no 1 o nível em nenhuma das categorias de análise específicas, e tão menos verificamos recuos significativos, no nível predominante do jogo de papéis.

Ao analisar os relatórios, deparamo-nos com dificuldades para situar o jogo praticado pelas crianças em determinado nível das categorias de análise específicas. Uma vez que, quando em determinado encontro, por várias vezes as ações da maior parte do número delas estiveram na direção do 2 o nível, na mesma sessão e em outras, frequentemente coexistiram sinais relacionados aos outros níveis.

Diante da dificuldade para posicionar as crianças em determinado nível das categorias de análise específicas, nós nos guiamos pelo nível predominante de jogo expressado na conjuntura das sessões consideradas no processo de análise.

Sena (2018) explica que para a criança que se encontra no 10 nível do jogo de papéis, o principal é atuar em relação ao objeto. Ao executar ações de ninar uma boneca, de manipular uma espada de plástico ou de pegar e depositar em espaços aleatórios pequenos objetos com a pá carregadeira de um tratorzinho 
de brinquedo, inconscientemente, ela já "[...] vislumbra um conteúdo novo, 'como na realidade'. Essa correlação mais profunda de modelo com suas ações reais é, nesta fase, o principio motor que traslada o jogo para um novo nível." (ELKONIN, 2009, p. 300).

Nesse novo nível (2ㅇ), há "[...] contradições que consistem, sobretudo, em que sobre o fundo geral do jogo inicia-se um processo de enriquecimento cada vez maior das ações executadas pela criança." (ELKONIN, 2009, p. 300). Os atos de cuidar da boneca, de manipular uma espada de plástico e de pegar objetos com a pá carregadeira de um tratorzinho de brinquedo inserem-se na lógica da vida, ligando-se a outros tipos de ocupações, como lavar as mãos e dar de comer à boneca; executar movimentos que demonstram ocorrer uma batalha imaginária com a espada de plástico e pegar objetos com o trator de pá carregadeira em determinado lugar e depositar em outro, por exemplo, na caçamba de um caminhão de brinquedo. O conteúdo que anteriormente permeava um só papel passa a ser dividido por dois papéis (ELKONIN, 2009).

$$
\begin{aligned}
& \text { Assim começa o terceiro } \\
& \text { nível, em cujo conteúdo } \\
& \text { lúdico já se vão } \\
& \text { manifestando } \\
& \text { claramente as regras } \\
& \text { que refletem um } \\
& \text { sistema de relações com } \\
& \text { outros participantes no } \\
& \text { jogo que assumem a } \\
& \text { protagonização deste } \\
& \text { ou daquele papel: a } \\
& \text { educadora e as crianças; } \\
& \text { a educadora, a } \\
& \text { cozinheira e as crianças; } \\
& \text { o médico e o paciente; } \\
& \text { o médico, a enfermeira } \\
& \text { e o paciente. (ELKONIN, } \\
& 2009, \text { p. 301). }
\end{aligned}
$$

Sena (2018) adverte que em comparação com o 10 e o 20, o 30 nível diz respeito a um estádio de desenvolvimento de outro tipo. "A diferença manifesta-se em que as ações objetais constitutivas do conteúdo do jogo passam para o segundo plano, e as funções sociais das pessoas sobem ao primeiro" (ELKONIN, 2009, p. 301); quer dizer, o brincar, até então comandado pelas ações lúdicas, agora passa a ser regido pelos papéis sociais dos personagens genéricos representados.
A transição do 3o para o 4ํㅡ nível segue sob a progressiva correspondência entre as relações lúdicas e as da vida real. À primeira vista, o 4 음 nel se assemelha ao 20

$[\ldots .$.$] já que tanto em um$
quanto em outro
manifesta-se com clareza a tendência para que as ações histriônicas verificar no livro correspondam à realidade da vida, ao modelo. A diferença primordial baseia-se, não obstante, em que enquanto no segundo nível a correspondência com a realidade da vida diz respeito à lógica externa das ações, à sua continuidade exterior, no quarto nível já é uma correspondência com a lógica das relações autênticas e seu sentido social. Nisso assenta a profunda diferença existente entre esses dois níveis. (ELKONIN, 2009, p. 301).

Respaldado em Elkonin (2009), Sena (2018) alerta que, no processo evolutivo do jogo de papéis, há muito em comum entre o 10 e o $2^{\circ}$ e o 3 o e o 4o níveis, havendo dois períodos fundamentais do desenvolvimento dessa modalidade de jogo. "No fundo, temos duas fases fundamentais, ou dois estágios, do desenvolvimento do jogo." (ELKONIN, 2009, p. 301). Na primeira fase, o conteúdo fundamental são as ações objetais orientadas pela lógica ditada pelas ações das pessoas, na realidade objetiva; na segunda, as relações sociais e o sentido social das atividades dos personagens genéricos envolvidos em íntima e fiel correspondência com as relações reais existentes no sistema de relações sociais.

A partir desse entendimento, reiteramos que, na $\mathrm{Fl}$, o 10 momento de intervenção (roda de conversa) cumpriu a função de enriquecer o conteúdo do jogo de papéis, já que a "[...] fonte fundamental do enriquecimento do conteúdo dos jogos infantis são as idéias que as crianças têm da 
realidade circundante; e se não as têm, não pode levar o jogo a cabo." (ELKONIN, 2009, p. 302).

Tipos de situações enriquecedoras das representações da realidade circundante, oportunizadas pelas rodas de conversa, se identificam nas descritas na 1a 2 2 e 3 a sessões da FI. Na roda de conversa da 1a sessão, destacamos a temática "brincar de casinha", na da 2a sessão, o argumento "médico" e, na da 3a sessão, o tema brincar de "casinha" articulado ao de "médico". $\mathrm{Na}$ roda de conversa dessas sessões, como em quase todas as outras que compuseram essa fase da investigação, esse momento foi marcado por amplos debates sobre os personagens que constituem os argumentos temáticos, como são suas atividades e com quais instrumentos as realizam. Em todas essas sessões, notamos a dialética presente na socialização das experiências pessoais relativas à oposiçãocontradição entre os modelos de ações e as maneiras de ser, de executar as atividades e de se relacionar dos personagens envolvidos.

Como decorrência das rodas de conversa, antes mesmo de brincar, as crianças souberam que existem pais que trabalham fora e que também auxiliam nos afazeres domésticos, que médicos utilizam o termômetro, o aparelho de medir pressão arterial e aplicam injeção, entre muitas outras tarefas. Contudo, conforme Elkonin (2009), somente quando a criança se coloca no lugar desses personagens, busca e realça as relações dessas pessoas com outras que integram os argumentos respectivos na realidade objetiva, reconstituindo as funções sociais, por meio das ações com os objetos dos diversos personagens genéricos e as relações entre eles. Essa condição possibilita à criança adotar a postura de um personagem no jogo e, ao assumir esse papel, se ver forçada a destacar da realidade as ações e relações dos adultos necessárias para cumprir a tarefa lúdica.

Ao refletir sobre o arcabouço teórico, os passos e os elementos encadeados no trabalho empírico, as análises e os resultados obtidos, Sena (2018) confia que os procedimentos de intervenção empregados colaboram para o atendimento dos direitos da criança da Educação Infantil, prescritos na versão final do texto da Base Nacional Comum Curricular (BRASIL, 2017).

Por esse ângulo e da consideração do "brincar" como objeto de intervenção pedagógica, conforme discutido em Sena (2018) a pesquisa propiciou situações de ensino e de aprendizagem respaldadas em experiências que possibilitaram às crianças "conviver" - quando, por meio de nossa intervenção, aprenderam a negociar o uso revezado dos brinquedos e a fazer escolhas dos companheiros, das temáticas e dos papéis reconstituídos nos episódios em que brincaram; "participar" - ao terem a curiosidade e a motivação aguçadas nos momentos da roda de conversa, da preparação conjunta (pelo professor e crianças) dos espaços/materiais e da intervenção pedagógica no jogo de papéis, durante o transcurso de seu acontecimento; "explorar" - os objetos e os diversos modelos de comportamento dos personagens genéricos socializados nas rodas de conversa e reconstituídos, através do brincar; "expressar" atitudes embasadas nos modelos de comportamento dos personagens genéricos que tiveram as formas de ser e de se comportar reconstituídas pelo brincar infantil; e "conhecerse" - ao imitarem as atividades dos personagens genéricos que constituem o sistema de relações sociais na realidade objetiva, de modo a perceberem o lugar que ocupam nesse sistema e, gradualmente, constituírem suas subjetividades (personalidades) nos planos pessoal e sociocultural.

\section{CONCLUSÕES}

Com base em Elkonin (2009) e Leontiev (2012), Sena (2018) explica que o conteúdo e a sequência de ações reconstituídas em episódios do brincar resultam das representações outrora subjetivadas pela criança. Pois, ao transgredir o conteúdo e/ou a sequência de ações, corre-se o risco de aniquilar a brincadeira. Por assim compreender, propomos que previamente e após o brincar, a criança seja submetida a situações de ensino que oportunizem a ampliação e o enriquecimento de suas representações acerca da maneira de ser e de agir dos personagens genéricos que compõem o sistema de relações sociais, dos respectivos modelos de comportamento e das formas como operam os objetos relacionando-se ao efetivarem suas atividades com esses objetos.

Em sintonia com o entendimento de que a criança em idade pré-escolar é incentivada a brincar por motivos ligados à necessidade da satisfação imediata do desejo de operar, não apenas os objetos aos quais tem acesso e já opera, mas também, e, principalmente, os de uso adulto; depreendemos que o 2 o momento de intervenção (direta), nomeado como o momento de preparação (conjunta) pelo(a) professor(a) e 
crianças dos espaços e dos materiais para a efetivação do brincar, se traduz em uma estratégia pedagogicamente bem mais rica e eficaz que a preparação prévia; já que esta é efetuada sem a participação efetiva das crianças.

De maneira consecutiva e imbricada à preparação conjunta dos espaços e dos materiais que compuseram as temáticas no decurso das sessões da $\mathrm{Fl}$, sucedeu $\mathrm{o}$ 3o momento de intervenção (também direta). Com base no arcabouço teórico e nas análises realizadas, ratificamos que para o(a) professor(a) intervir no jogo de papéis de forma a não prejudicar o desdobramento do conteúdo e das sequências de ações, é imprescindível que sua dimensão brincante esteja desenvolvida, exercitada e que ele conheça e se paute no desenvolvimento real das crianças, relativo aos elementos que constituem e conduzem a temática, em certo episódio do brincar. Somente assim ele terá condições de sugerir nas tramas manifestadas, a inclusão de novos objetos substitutos (neutros e representativos) e de personagens centrais e complementares, sem correr o risco de paralisar o brincar infantil, ensejando a complexificação e o aumento de turnos de ações e de consequentes séries interativas cada vez mais elaboradas.

Como a de outro docente, compete à prática educativa do(a) professor(a) pré-escolar dispor de caráter interventivo, de maneira a transcender a função de preparação, de observação e de formulação de registros do brincar infantil. Em decorrência dessa compreensão, arrolamos argumentos suficientes para inferir que no contexto da educação formal da pré-escola, o jogo de papéis deve ser estimado como atividade-guia do psiquismo das crianças contemporâneas em idade pré-escolar.

Para investir nessa intenção, é imprescindível que o(a) professor(a) compreenda os vínculos existentes entre os elementos mobilizados em sua prática educativa (nesse caso, mediante o ato interventivo no jogo de papéis) e as práticas sociais presentes na realidade objetiva do sistema de relações sociais. Nessa tendência e de modo específico (propriamente pedagógico), por meio do exemplo da intervenção pedagógica no jogo de papéis esquadrinhado pela tese, cremos que a investigação contribuiu para com 0 enriquecimento e a ampliação dos conhecimentos referentes às possibilidades e limites do jogo no contexto educacional.
Ao contemplar os objetivos da pesquisa, contribuímos para com a minimização do problema revelado na constatação de raríssimos estudos propositivos voltados às formas e meios de se praticar intervenções pedagógicas indiretas e diretas no jogo de papéis. Nesse sentido, a investigação clarificou o entendimento de como a intervenção pedagógica pode alinhar o movimento dialético causado pelos elementos envolvidos na simultaneidade dos avanços do nível de jogo e do psiquismo infantil. Essa demonstração desafia pesquisadores e formadores de cursos de pedagogia a revisar seus modos de alinhar a formação teórica e a constituição-aprimoramento da práxis pedagógica dos professores da Educação Infantil e dos estudantes dos cursos de pedagogia e áreas afins.

Em síntese, nos deparamos com argumentos suficientes para elevar o que era pressuposto inicial ao status de tese da pesquisa. Isto é, tecemos argumentos suficientes para inferir que "a intervenção do(a) professor(a) préescolar no jogo de papéis não deve se limitar à circunscrição da organização prévia dos espaços e dos materiais para a efetivação do brincar infantil. Além disso, cabe a esse(a) professor(a) intervir de forma indireta e direta nessa espécie de atividade, com vistas a promover o avanço do nível do jogo de papéis e, por consequência, o desenvolvimento psíquico da criança préescolar."

\section{REFERÊNCIAS}

ADES, C. Um adulto atípico na cultura das crianças. In: MÜLLER, F.; CARVALHO, A. M. A. Teoria e prática na pesquisa com crianças: diálogos com William Corsaro. São Paulo: Cortez, 2009. p. 127-136.

BRASIL. Ministério da Educação. Ministério de Estado da Educação. Secretaria Executiva. Secretaria de Educação Básica. Base Nacional Comum Curricular: Educação é a Base. Brasília: MEC/MEE/SE/SEB, 2017.

CARVALHO, E. Totalidade como categoria central na dialética marxista. Revista do Instituto de Estudos Socialistas, n. 15, p. 177-193, out. 2007.

ELKONIN, D. B. Psicologia do jogo. 2. ed.São Paulo: Martins Fontes, 2009. 
KERLINGER, F. N. Metodologia da pesquisa em Ciências Sociais: um tratamento conceitual. São Paulo: Pedagógica e Universitária, 1979.

LEONTIEV, A. N. Os Princípios psicológicos da brincadeira pré-escolar. In: VYGOTSKY, L. S.; LURIA, A. R.; LEONTIEV, A. N. Linguagem, desenvolvimento e aprendizagem. São Paulo: Ícone, 2012.p. 119-142.

MARTINS, L. M. Introdução aos fundamentos epistemológicos da psicologia sócio-histórica. $2015 . \quad$ Disponível em: $<$ https://www.google.com.br/?gws $r d=s s l \# q=i n t r$ odu\%C3\%A7\%C3\%A30+aos+fundamentos+episte mol\%C3\%B3gicos+da+psicologia+s\%C3\%B3cio+hi st\%C3\%B3rica>. Acesso em: 28 dez. 2015.

PINO, A. As marcas do humano: as origens da constituição cultural da criança na perspectiva de Lev S. Vigotski. São Paulo: Cortez, 2005.

SENA, S. A dialética entre a intervenção pedagógica no jogo de papéis e o desenvolvimento psíquico da criança contemporânea em idade pré-escolar. 2018. 201 f. Tese (Doutorado em Educação) - Faculdade de Ciências e Tecnologia, Universidade Estadual Paulista, Presidente Prudente, 2018.

VYGOTSKY, L. S. A formação social da mente: o desenvolvimento dos processos psicológicos superiores.7. ed. São Paulo: Martins Fontes, 2007.

Submetido: 02/09/2018

Correções obrigatórias: 07/12/2018

Aceite final: 01/03/2019 